\title{
Belphégor
}

Littérature populaire et culture médiatique

15-1| 2017

1936: les Jeux olympiques dans la presse

internationale

\section{Les Jeux olympiques de Berlin vus par la photographie de presse}

Mélodie Simard-Houde

\section{CpenEdition}

Journals

Electronic version

URL: http://journals.openedition.org/belphegor/871

DOI: 10.4000/belphegor.871

ISSN: 1499-7185

Publisher

LPCM

Electronic reference

Mélodie Simard-Houde, « Les Jeux olympiques de Berlin vus par la photographie de presse »,

Belphégor [Online], 15-1 | 2017, Online since 06 July 2017, connection on 01 May 2019. URL : http:// journals.openedition.org/belphegor/871 ; DOI : 10.4000/belphegor.871

This text was automatically generated on 1 May 2019.

\section{(c) (†) $\odot$}

Belphégor est mis à disposition selon les termes de la Licence Creative Commons Attribution - Pas d'Utilisation Commerciale - Pas de Modification 4.0 International. 


\title{
Les Jeux olympiques de Berlin vus par la photographie de presse
}

\author{
Mélodie Simard-Houde
}

1 À l'époque où prennent place les Jeux olympiques de Berlin, la photographie est déjà solidement implantée dans la presse française, quotidienne comme hebdomadaire. Les premières expérimentations de reporters photographes, qui ont vu le jour dès la fin du $\mathrm{XIX}^{\mathrm{e}}$ siècle, ont laissé place à une systématisation de la pratique et du réseau de distribution: comme pour les dépêches et informations d'actualité, les journaux font appel à des agences ${ }^{1}$ pour obtenir les photographies de dernière heure. Plusieurs quotidiens disposent de leur propre équipe de reporters photographes, dont la plus développée est sans doute celle de Paris-Soir ${ }^{2}$, tout comme les hebdomadaires illustrés, tel $\mathrm{Vu}$, qui font appel à la fois aux agences et à des photographes indépendants (à l'instar de Germaine Krull ou d'André Kertész). Enfin, il n'est pas rare que les reporters de la presse écrite se fassent eux-mêmes photographes, grâce à la portabilité et à la maniabilité de la nouvelle génération d'appareils nés dans les années vingt, comme le Leica et le Rolleiflex.

Conformément au mot de Jean Prouvost, directeur de Paris-Soir, la photographie apparaît comme un élément indispensable de la couverture de l'actualité des années trente: «L'image est devenue la reine de notre temps. Nous ne nous contentons plus de savoir, nous voulons voir. Tout grand journal d'information tient à placer à côté de la nouvelle, le document photographique qui, non seulement l'authentifie, mais en donne la physionomie exacte ${ }^{3}$.» Au cours des Jeux de Berlin, on retrouve des photographies de l'événement dans la très grande majorité des titres de presse dépouillés. Seuls certains hebdomadaires littéraires et satiriques font exception (Gringoire, Vendredi, Je suis partout, Le Charivari, Le Canard enchaîné), de même que deux quotidiens, L'Action française et Le Temps qui, de manière générale, font très peu usage de ce médium.

3 Il est indéniable que la photographie est alors investie, aux yeux du grand public, d'une valeur d'attestation, comme l'indique la déclaration enthousiaste de Prouvost. Cette croyance est héritière d'un discours mis en place dès les débuts de la photographie et qui perdure dans la presse quotidienne des années trente, où l'on parle couramment de « saisie » et de « document » photographiques. L'« œil mécanique » de la caméra montre 
et, de ce fait, atteste, même si, en parallèle, le champ de la photographie d'art et les revues spécialisées, dont $\mathrm{Vu}$, tentent d'éduquer le regard du spectateur et de déconstruire l'idée communément admise d'objectivité photographique ${ }^{4}$. De plus, des polémiques autour de la dénonciation de trucages photographiques dans la presse des années trente vont mettre à mal la notion d'objectivité de l'image ${ }^{5}$. Dès lors, la photographie peut aussi se concevoir comme image manipulée, truquée, montée, retouchée, dont on perçoit, au moins par moments, le potentiel de propagande (ou de contre-propagande) politique. La couverture des Jeux olympiques, de par l'investissement idéologique dont cet événement est l'objet, met en relief le balancement entre une photographie reçue comme médiation transparente, fenêtre ouverte sur l'événement, et une photographie retouchée ou encadrée par l'énonciation éditoriale, susceptible de contenir une charge idéologique implicite. L'intervention de la rédaction sur la photographie renferme en effet un potentiel de détournement de la propagande nazie qui sera parfois exploité.

4 Si la photographie est, globalement, omniprésente dans la couverture des Jeux de Berlin, la place que les différents titres lui accordent et le traitement qu'ils en offrent varient en fonction de la politique éditoriale de chacun. Certains titres de la presse quotidienne Paris-Soir, L'Intransigeant, Le Figaro, Le Matin, Le Progrès - lui consacrent des pages ou des rubriques spécifiques, à l'intérieur des pages sportives ou en dernière page, où plusieurs événements sont susceptibles de se trouver juxtaposés et forment une mosaïque d'actualité non sans significations implicites, comme on le verra. Tandis que chez d'autres - Le Petit Parisien, Le Petit Journal, L'Écho de Paris, L'Humanité, La Croix -, la photographie est plus dispersée, se concentre en "une» ou se retrouve isolée en page des sports. Le traitement de la photographie est lui aussi fluctuant, certaines rédactions pratiquant le photomontage, d'autres non, tout comme le sont les sources auxquelles s'approvisionnent les journaux.

5 À cet égard, l'information dont nous disposons est lacunaire. La presse quotidienne ne fait que rarement mention des sources des photographies qu'elle publie, qu'il s'agisse de ses propres reporters photographes ou d'images fournies par les agences. Si la presse hebdomadaire est plus encline à les citer ${ }^{6}$, cette précision est souvent occultée. Plusieurs indices indiquent cependant que la couverture des Jeux de Berlin par les 1800 représentants de la presse étrangère ${ }^{7}$ a pu s'effectuer dans une relative liberté, contrairement à celle des Jeux d'hiver de Garmisch's. À l'occasion, la presse signale, de manière implicite ou explicite, la présence de photographes français envoyés sur les lieux : ainsi, dans L'Écho de Paris, une photographie mettant en scène l'envoyé spécial Jean Routhier donne à penser qu'un photographe du même journal l'accompagnait ${ }^{9}$. Dans Paris-Soir, on retrouve à quelques reprises la mention « Par bélino de Berlin ${ }^{10}$ ", ou encore "Photo de notre correspondant particulier transmise de Berlin à "Paris-Soir" par bélinogramme ${ }^{11} »$. Toutefois, une telle précision demeure isolée et n'a pas été remarquée dans d'autres titres. Le lecteur de la presse est plus souvent laissé dans l'ignorance quant à la provenance des images. L'absence de crédits photographiques dans Paris-Soir (en dehors des mentions citées) ou dans L'Intransigeant est étonnante, car il est d'usage, dans le langage éditorial à vocation autopromotionnelle de ces quotidiens, d'y renvoyer. Ainsi, L'Intransigeant ne manque pas de révéler le travail de ses photographes pendant la guerre civile en Espagne, au même moment ${ }^{12}$, mais nulle mention n'est faite relativement à la couverture photographique des Jeux.

6 La récurrence de certains clichés laisse croire, par ailleurs, que la presse s'est amplement approvisionnée auprès des agences, voire du service de presse organisé sur place ${ }^{13}:$ «n 
service de photos de presse incroyablement rapide et abondant réduisit considérablement la publicité négative susceptible d'émaner des journalistes étrangers résidents qui, eux, ne pouvaient être qu'en partie dupés ${ }^{14}$ ", signale Josef Schmidt. Parmi les clichés récurrents, on peut citer une vue aérienne du village olympique, où s'alignent les immeubles selon une géométrie parfaite qui n'est pas sans évoquer l'ordre et la discipline d'un camp militaire.

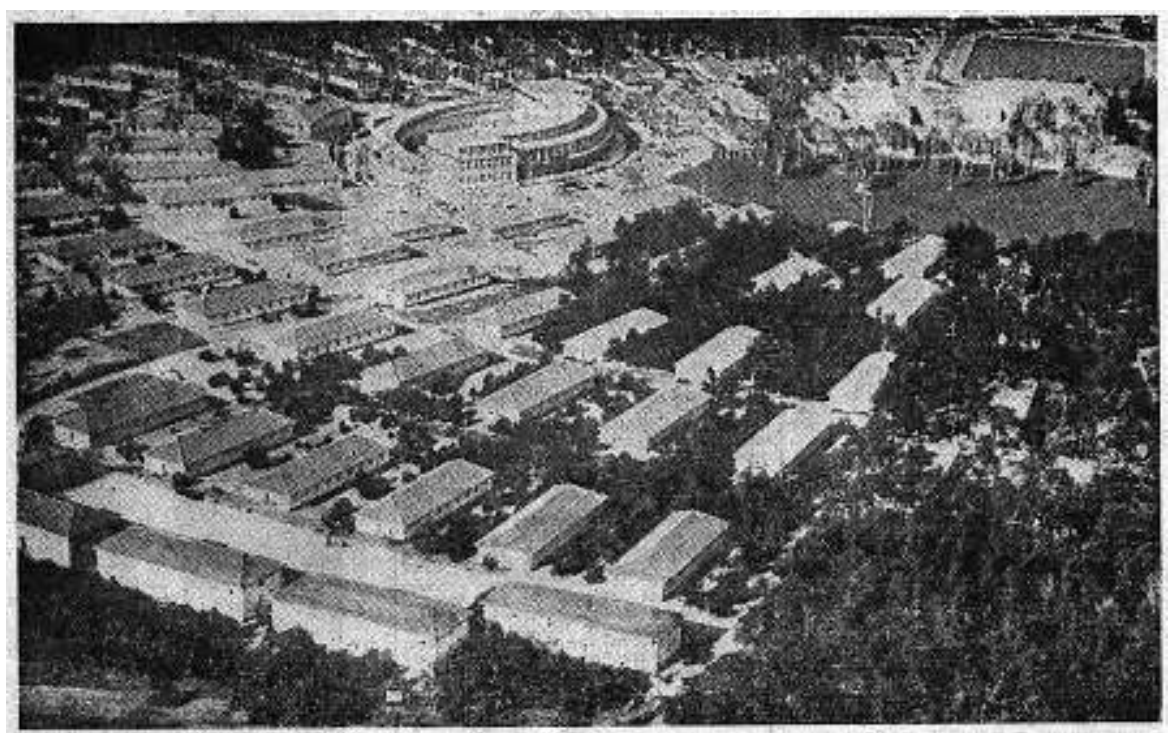

Cette image est publiée dans Le Petit Journal, 30 juillet 1936, p. 8. Le même cliché est reproduit dans La Croix, 31 juillet, une, et dans Le Figaro, 8 août, p. 10, avec quelques variations de qualité ou de cadrage.

7 Mais l'un des cas les plus remarquables de photographie récurrente concerne un moment des cérémonies d'inauguration. L'allumage de la flamme olympique est représenté par divers journaux à partir de clichés pris simultanément et d'un point de vue similaire. C'est essentiellement le recadrage de la photographie ou une légère modification de l'angle de prise de vue qui instaure une variation d'un quotidien à l'autre. Deux types de plans sont repérables : le premier est une vue d'ensemble en plongée, qui représente la scénographie du stade avec les étendards nazis et les militaires en uniforme en arrièreplan, à l'instar de la photographie publiée par L'Illustration. 


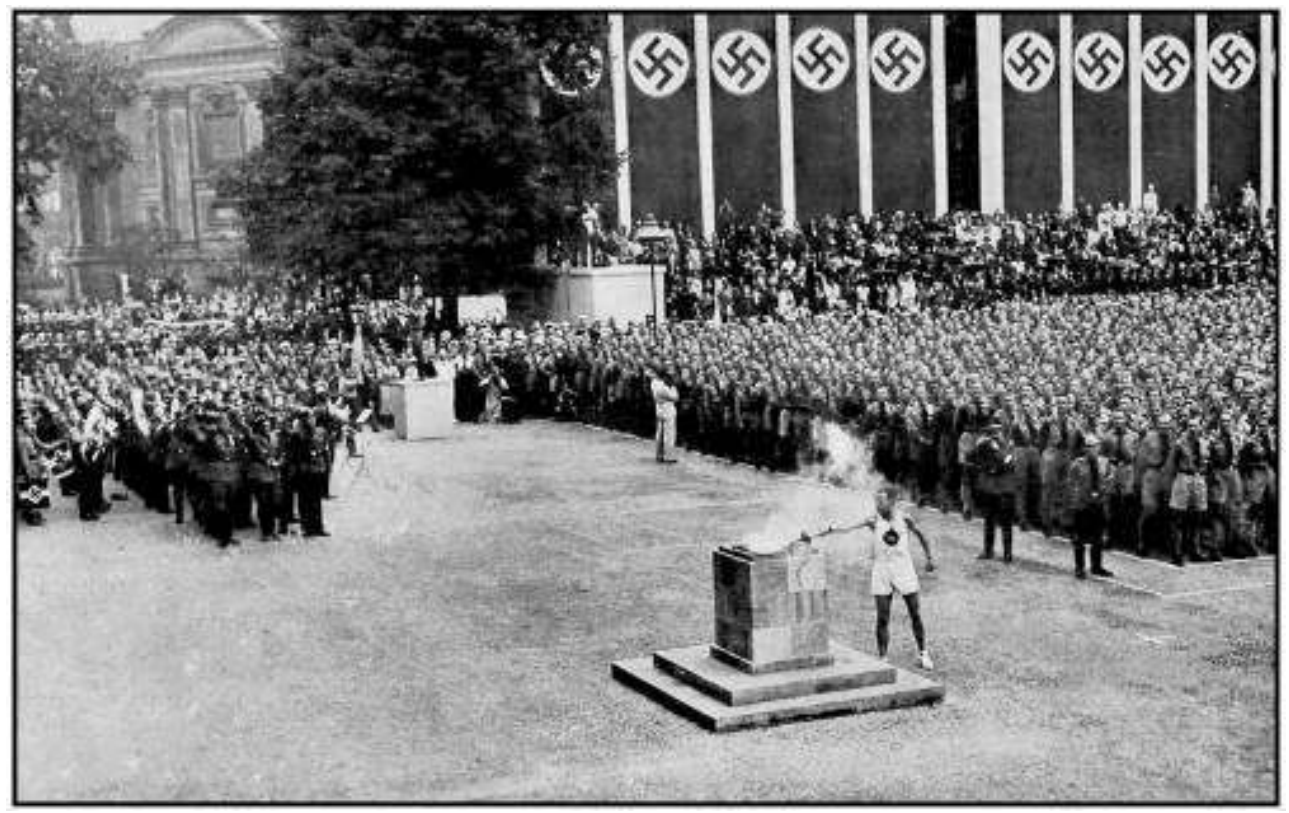

«La Xle Olympiade », dans L'Illustration, 8 août 1936, p. 442-443.

8 Le second offre un cadrage resserré sur le geste du porteur de flamme, qui a pour effet d'occulter une bonne partie de la mise en scène à teneur idéologique. On en trouve diverses variations. La première, publiée dans Le Progrès, se resserre sur le geste du porteur de flamme et oblitère la foule ordonnée des militaires, tout en laissant voir les étendards nazis. On peut remarquer en outre qu'elle a été symétriquement inversée par rapport à l'image précédente.

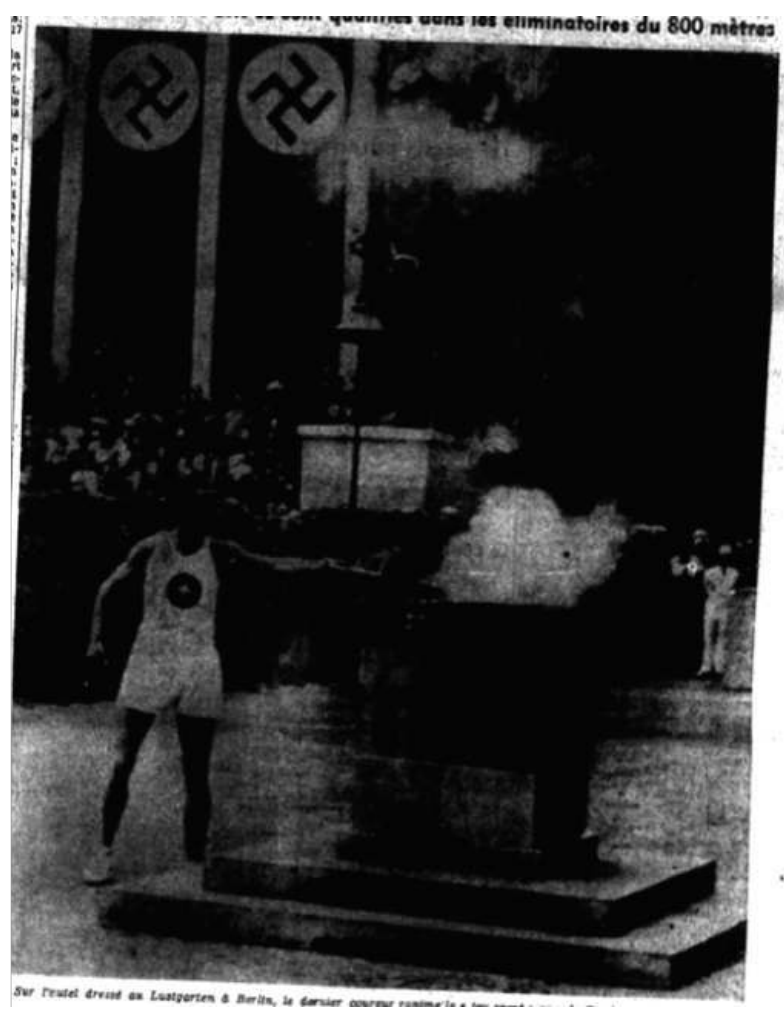

« Le dimanche sportif », dans Le Progrès, 3 août 1936. 


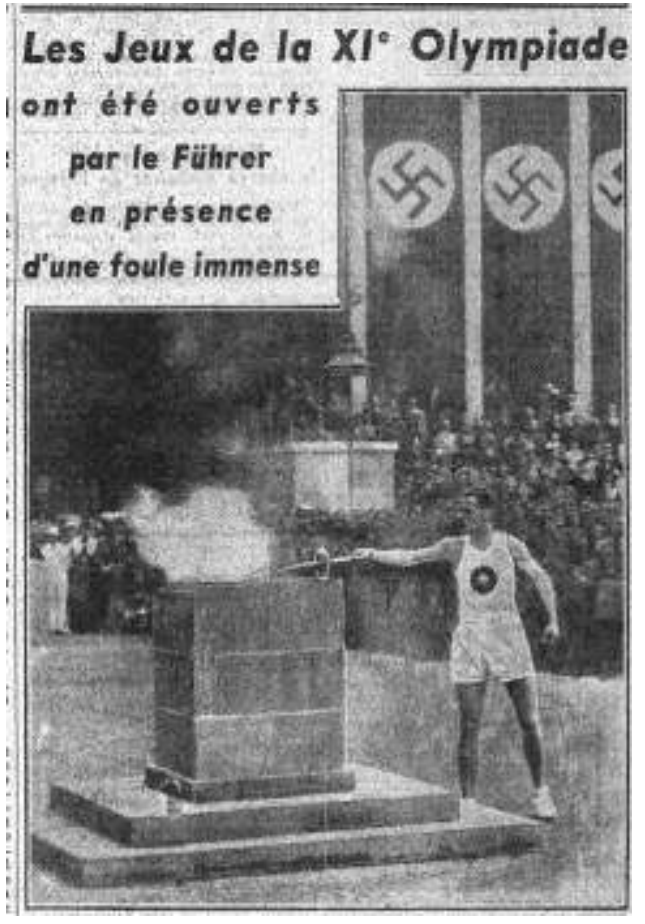

Le Petit Parisien, 2 août 1936, une.

Comme on peut le voir dans l'exemple précédent, le même cliché était employé, la veille, avec un cadrage quasi identique, à la une du Petit Parisien, en conservant l'orientation originale de l'image. Enfin, L'Auto propose à nouveau ce cliché, mais avec un cadrage encore plus resserré sur le geste de l'athlète, où cette fois même les insignes nazis qui ornent le haut des étendards disparaissent ${ }^{15}$; c'est aussi le cas dans Match ${ }^{16}$.

L'exemple indique qu'un simple recadrage ou qu'une légère variation du point de vue modifie la portée idéologique d'une image formatée et diffusée à large échelle par un service de presse dont l'instauration vise à l'évidence à contrôler, dans la mesure du possible, la représentation des Jeux. Ce contrôle de l'image, susceptible d'être mis en échec par le traitement ultérieur de la photographie par la presse, fait partie des mesures prises par le Reich pour renvoyer une représentation positive de l'Allemagne nazie et assurer l'efficacité de l'«habillage idéologique ${ }^{17}$ » des Jeux. Il s'insère aussi dans un dispositif plus large et soigneusement prévu de spectacularisation et de médiatisation de l'événement, prolongé par la radio, la télévision et le cinéma.

\section{Le spectacle des corps}

11 Les Jeux olympiques de Berlin ont en effet été l'objet d'une grande préparation ${ }^{18}$ et d'une mise en scène spectaculaire où chaque élément était pensé pour assurer la récupération efficace de l'olympisme et de ses symboles par l'idéologie nazie ${ }^{19}$. Ceux-ci saturent l'événement et son iconographie ; le spectateur des Jeux, comme celui de la photographie de presse, ne peut qu'en être abreuvé. Un stade sportif colossal, rempli par une foule en liesse, où défilent les contingents de tous les pays, tandis que saluts olympique et hitlérien se confondent, fournit la scène. L'ancrage historique des Jeux dans un passé hellénique dont se réclame le national-socialisme est assuré par le trajet de la flamme olympique ralliée depuis la Grèce - une tradition inaugurée en $1936^{20}$. Ses feux, allumés 
par les rayons du soleil, rappellent l'origine mythique du peuple aryen ${ }^{21}$. La référence à l'Antiquité est encore convoquée par les couronnes de lauriers décernées aux vainqueurs et par les statues des sculpteurs Arno Breker et Joseph Thorak qui ornent le complexe du stade $^{22}$ et rendent visible le corps esthétique de l'athlète à l'épreuve. Les drapeaux qui pavoisent la ville et le stade évoquent, certes, l'idéal universaliste des Jeux, mais la place prépondérante accordée aux étendards nazis, notamment lors de la cérémonie d'ouverture du $1^{\mathrm{er}}$ août, rappelle les grands rassemblements politiques du Reich, tels qu'ils ont été mis en scène dans le Triomphe de la volonté (1935) de Leni Riefensthal.

Tous ces éléments constituent la scénographie préalable des Jeux. Celle-ci opère, avant même la photographie, un formatage idéologique de l'événement qui oriente et informe l'image de presse. À bien des égards, on pourrait soutenir que cette scénographie a été préparée par la symbolique du national-socialisme élaborée dans les arts visuels (peinture, sculpture, théâtre Thing) pendant les années vingt et la première moitié des années trente ${ }^{23}$. Les Jeux de Berlin peuvent se concevoir en ce sens comme un immense musée vivant qui réalise, dans l'événement collectif, les conceptions nationales-socialistes de l'art, tout en présentant le caractère actif de l'expérience vécue (l'Erlebnis $\left.{ }^{24}\right)$. Ils sont un exemple remarquable d'« œuvre d'art totale » au sens où l'entendaient les nazis ${ }^{25}$.

Le photographe de presse doit donc composer avec une entreprise de propagande qui formate l'événement, précède la capture de l'image et dont il n'est peut-être pas toujours pleinement conscient ${ }^{26}$. En conséquence, la photographie du service de presse et même celle, non contrôlée, d'un reporter photographe étranger, est porteuse d'une charge idéologique implicite; en relayant la scénographie des Jeux de Berlin, elle en relaie aussi l'esprit et la signification, contenus dans la mise en scène et les symboles déployés. La récurrence des scènes et des motifs véhiculés par les photographies publiées dans la presse française, si elle a sans doute découlé en partie de la diffusion à large échelle de photographies d'agence ou de service de presse, tend à valider le constat d'un regard des reporters photographes orienté par la scénographie de l'événement.

Parmi ces motifs récurrents, la mise en scène des corps occupe une place importante. Le corps est bien sûr en premier lieu celui, individuel, du sportif; il offre alors une incarnation possible du type idéal aryen (inspiré de l'hellénisme ${ }^{27}$ ), athlétique et musculeux, une "idéologie corporelle ${ }^{28}$ » où se rencontrent le sport et le fascisme. La capture du corps en mouvement réactive la référence à la civilisation grecque préparée par la scénographie des Jeux, par exemple dans les épreuves d'athlétisme, où les gestes du lancer $\mathrm{du}$ javelot et du disque rappellent les poses des statues antiques - un rapprochement que ne manquera pas d'exploiter Leni Riefenstahl dans Les Dieux du stade ${ }^{29}$ 


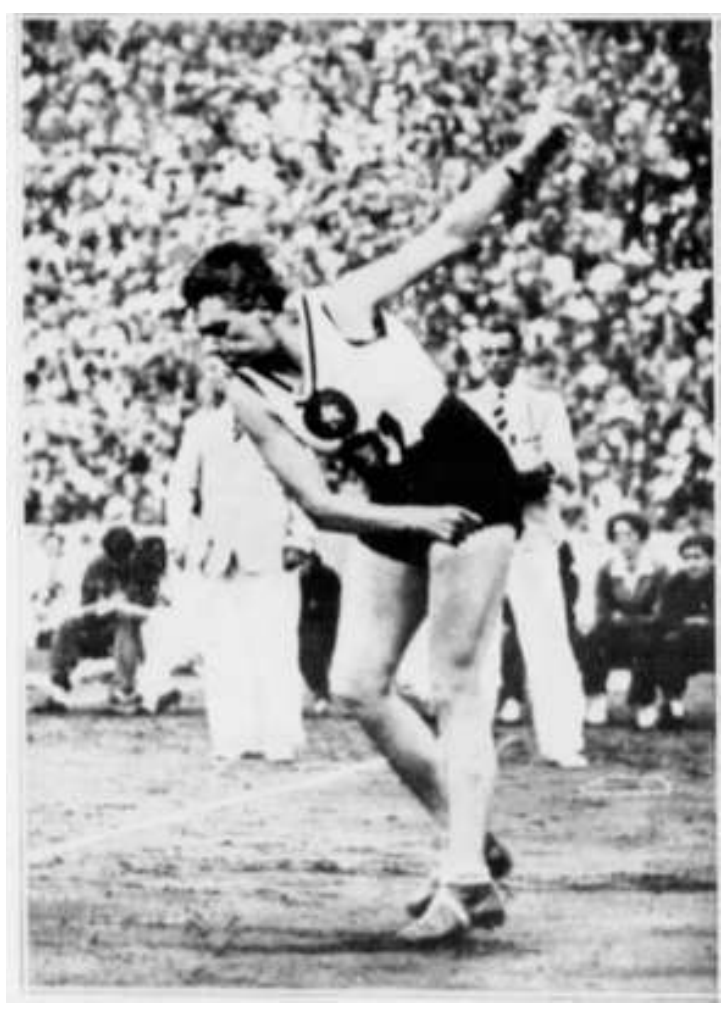

"L'Allemande Filly Fleischer qui a battu le record féminin du javelot avec un jet de 45m18 », dans L'Illustration, 15 août 1936.

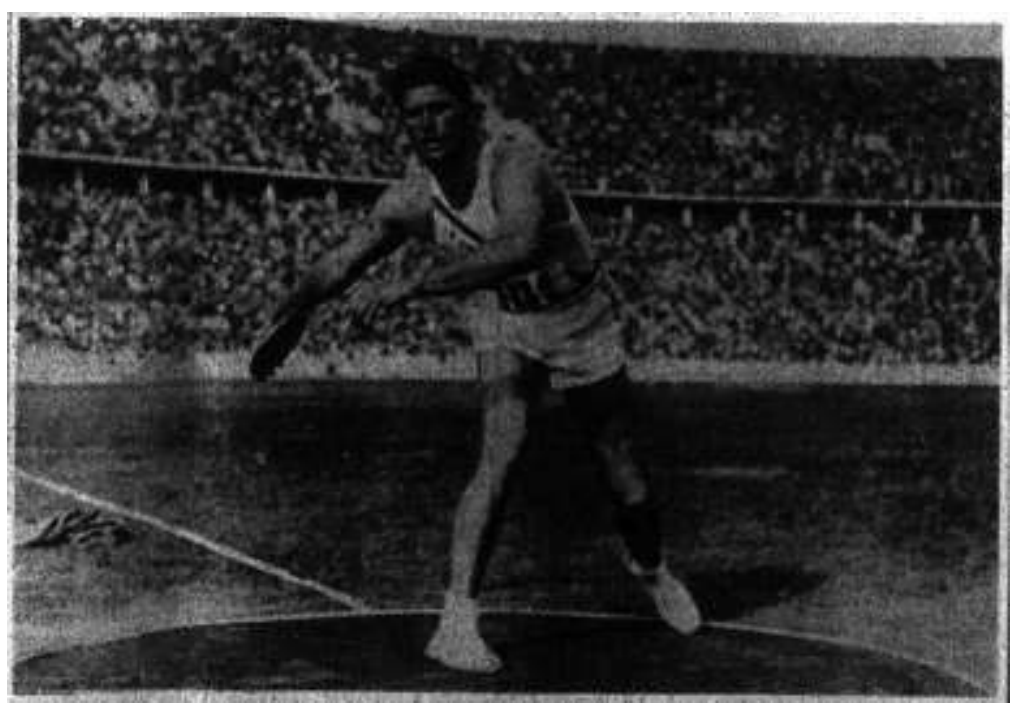

«L'Américain Carpenter, lançant le disque », dans Le Progrès, 7 août 1936, une.

15 Mais si la photographie de presse semble renvoyer, pour un œil averti, aux statuaires antiques, ce n'est que de manière somme toute implicite. Sans exalter l'idéologie du corps aryen, c'est, plus largement, le corps sportif qui est mis en scène dans une photographie esthétisante, qui célèbre la perfection, la beauté, la grâce, la vitesse ou la force des athlètes dont la caméra a fixé le mouvement. La foule du stade fournit bien souvent l'arrière-plan où se découpe le corps athlétique (comme dans les deux images précédemment citées), mais le ciel est également convoqué. Il accentue le traitement esthétisant du corps en détachant celui-ci de l'événement et de sa spectacularisation, 
pour en restituer une vision presque abstraite. L'agencement des formes et le contraste des ombres prennent le pas sur la restitution du déroulement d'une épreuve sportive.

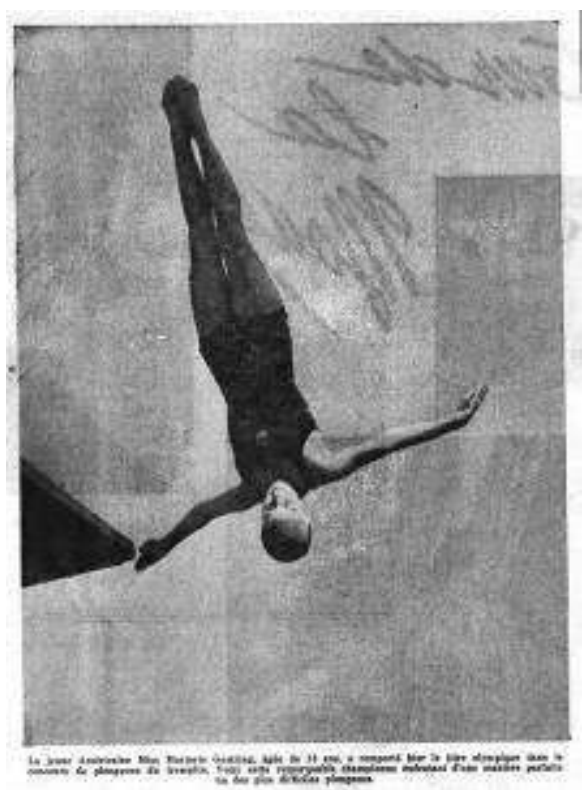

Le Figaro, 13 août 1936, p. 8

La photographie de presse rejoint ici les expérimentations esthétiques de l'avant-garde de l'entre-deux-guerres, sensible à la capture du mouvement et à la mise en scène du corps sportif, dans une visée d'exploration des spécificités techniques de la saisie de l'œil mécanique $^{30}$. Le souci esthétique se retrouve ainsi à l'avant-plan dans la représentation des diverses épreuves - course à pied et athlétisme, natation, plongeon, cyclisme, boxe, etc. -, au point où il semble parfois se substituer à un éventuel discours critique sur les Jeux, en maintenant la fiction d'un universalisme autorisé par l'égalité esthétique et démocratique des corps dans l'épreuve. C'est une telle égalité que semble signaler un photomontage comme celui du Petit Parisien, où sont juxtaposés en action les Américains Jesse Owens et Glenn Hardin, de même que le Français Louis Hostin, vainqueurs dans leur épreuve respective. 


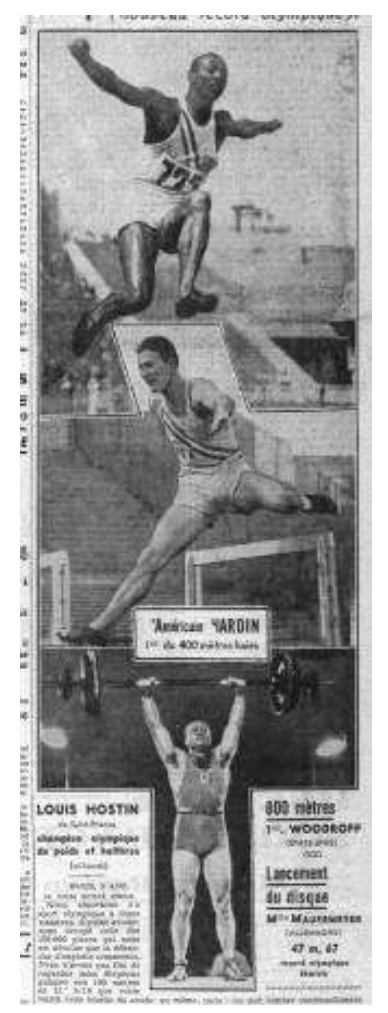

Le Petit Parisien, 5 août 1936, une.

17 Ce type de montage de mouvements sportifs, qui synthétise en un coup d'œil les résultats de la journée, est relativement fréquent et semble privilégier les athlètes américains, anglais et français au détriment des allemands. On peut en citer un autre exemple, issu de Paris-Soir, où figurent l'Américain Carpenter, l'Anglais Whitlock et, à nouveau, Jesse Owens.

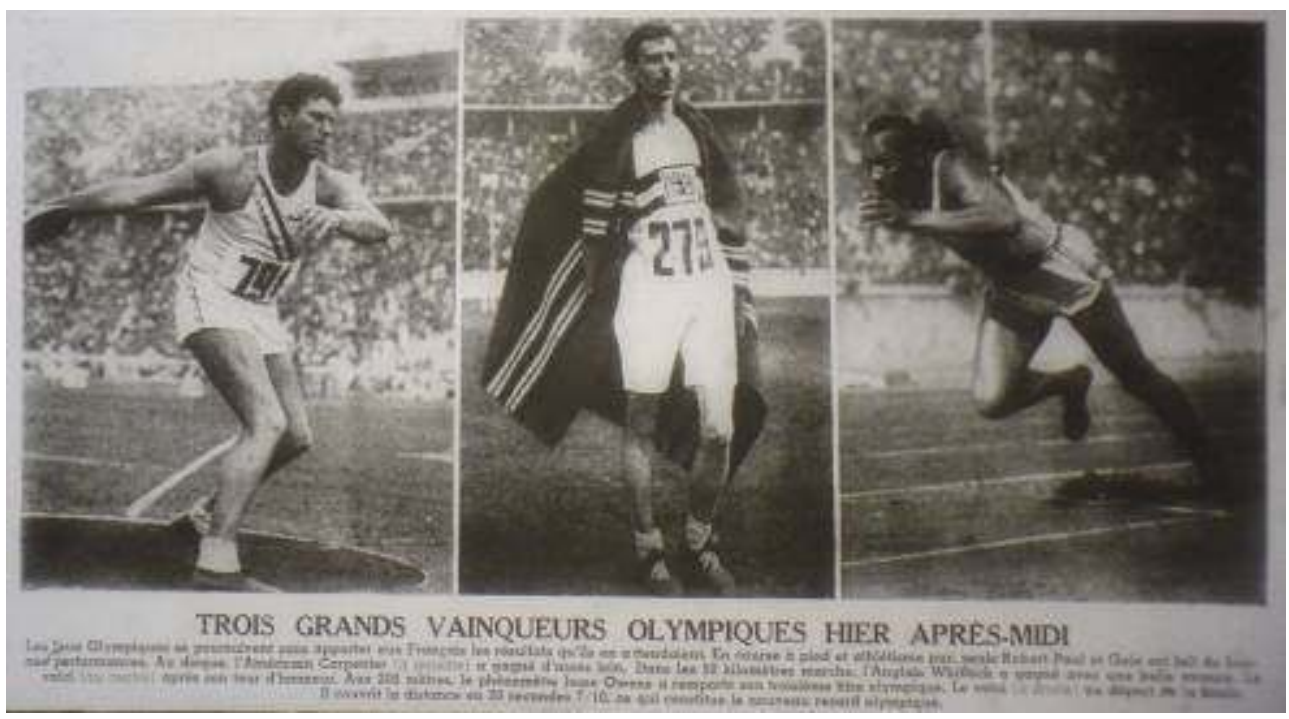

Paris-Soir, 7 août 1936, dernière page.

18 Comme il a été signalé par ailleurs, les exploits d'Owens, constamment rapportés et illustrés, apportent pour certains quotidiens un « démenti à l'aryanisme nazi tout autant qu'aux lois racistes américaines ${ }^{31}$ » et constitueraient la preuve de Jeux ouverts qui ne trahissent pas l'idéal universaliste de l'olympisme. Cependant, de fait, ils servent surtout 
de paravent au racisme qui a entraîné l'exclusion des athlètes juifs de la délégation allemande, en dépit des promesses des dirigeants nationaux-socialistes, des pressions internationales et des menaces de boycott. La célébration de l'esthétisme du corps sportif agit en quelque sorte à la manière d'un leurre, tout comme elle servira après la Seconde Guerre mondiale d'échappatoire à Leni Riefenstahl pour se défendre d'avoir donné avec Les Dieux du stade un film de propagande nazie ${ }^{32}$.

Par ailleurs, le corps individué de l'athlète ne parvient pas tout à fait à occulter celui, militaire, des bataillons de gymnastes et de SS, ou encore celui de la foule, omniprésente, qu'elle soit le principal sujet de la photographie ou forme l'arrière-plan des prouesses sportives. Les représentations de ces corps collectifs témoignent de manière remarquable de l'impact visuel et de la dimension idéologique de la scénographie des Jeux, dont la photographie peut difficilement faire abstraction. À l'instar des habitations alignées du village olympique, les corps des gymnastes ou des « Jeunesses hitlériennes » mis en scène lors des cérémonies incarnent l'ordre et illustrent la proximité entre sport et enrôlement militaire dans l'idéologie nazie. Ils affirment l'aptitude du corps sportif rompu à la discipline et aux exercices militaires et introduisent une confusion entre ces deux domaines, tout comme l'assimilation du salut hitlérien et du salut olympique esquissé par des hommes en uniforme en arrière-plan de la première photographie.

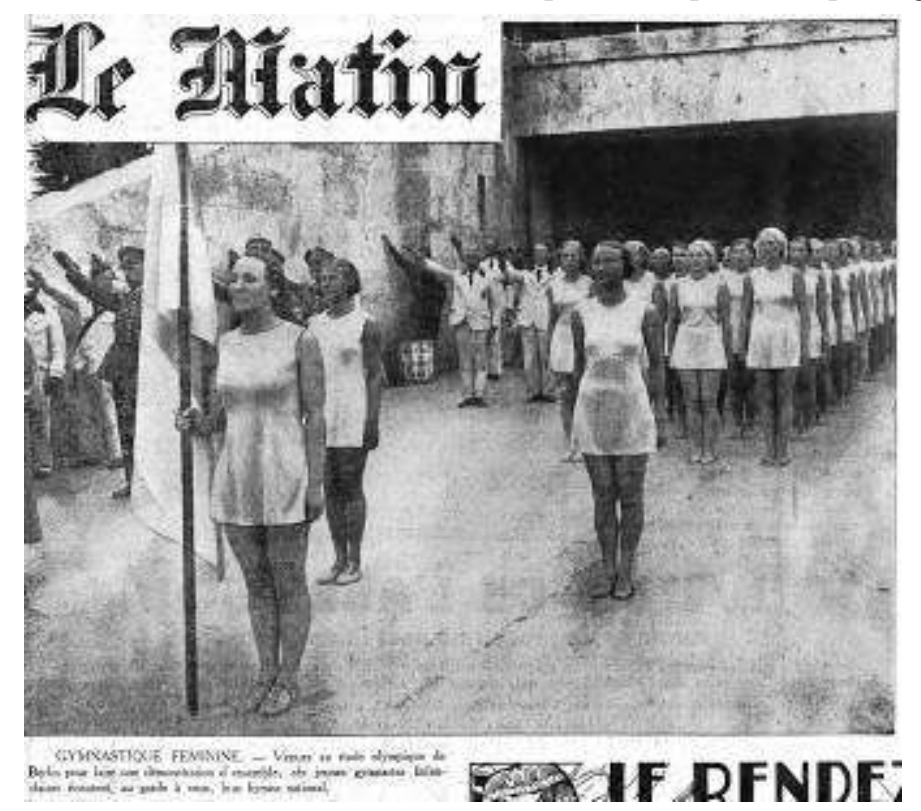

"Gymnastique féminine. - Venues au stade olympique de Berlin pour faire une démonstration d'ensemble, ces jeunes gymnastes finlandaises écoutent, au garde à vous, leur hymne national. », dans Le Matin, 9 août 1936, p. 8. 


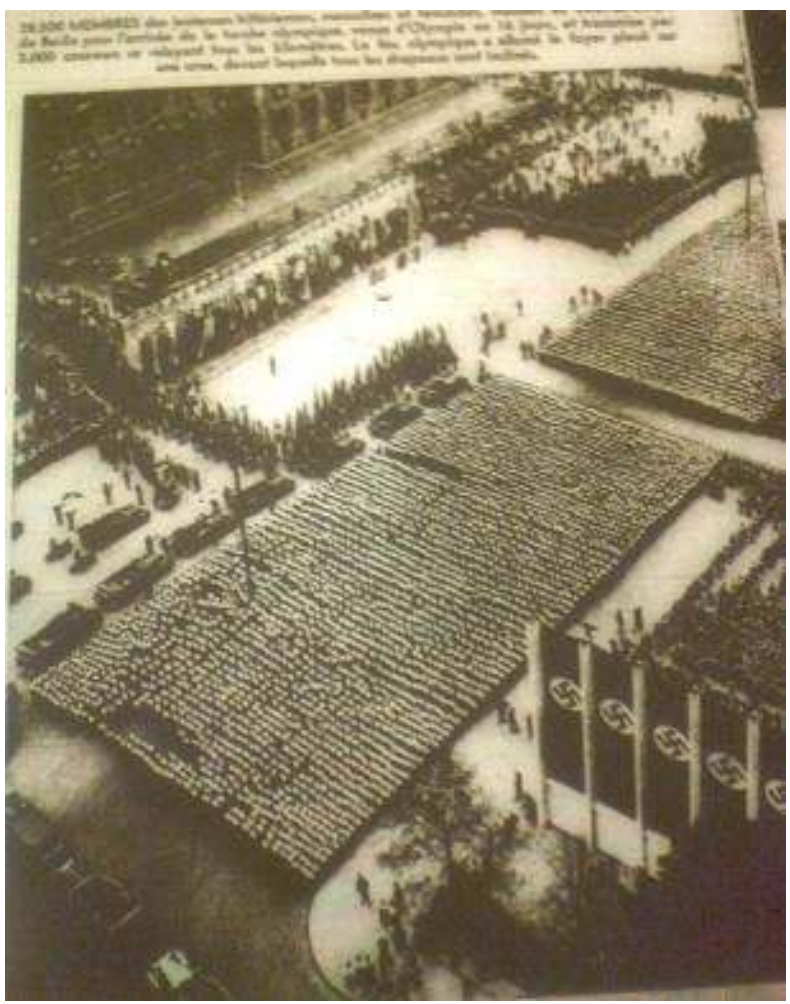

Vue aérienne des « 28.500 membres des Jeunesses hitlériennes », dans Le Miroir des sports, 4 août 1936.

De ces mises en scène de corps collectifs émane une homogénéité frappante, qu'il s'agisse de celle qui se dégage des poses rigides et des uniformes (avant-dernière image), de celle produite par la dissolution de l'identité au sein de la masse compacte et géométrique du groupe (dernière image) ou par la jeunesse des athlètes, qui apparaissent comme autant de copies d'un idéal de pureté, de santé et d'énergie.

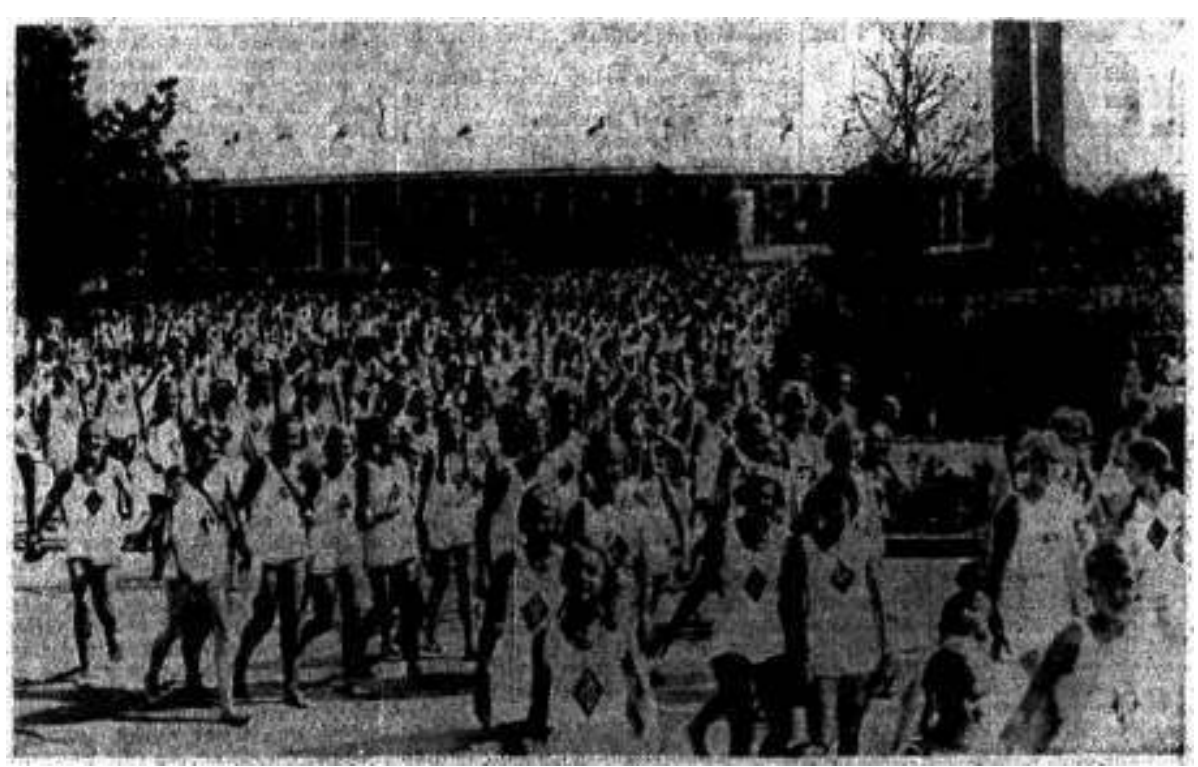

"Un groupe de femmes sportives allemandes arrivent au Stade Olympique », Le Progrès, 2 août 1936, une. 
Ce corps collectif homogène est aussi incarné par les délégations d'athlètes circulant dans le stade lors des cérémonies d'ouverture. Leur alignement en rangs, leurs uniformes, la présence du porte-drapeau sont autant d'éléments qui rappellent le défilé militaire, que l'on parle des délégations allemandes ou, comme dans l'image suivante, qui représente la délégation française, des autres nations.

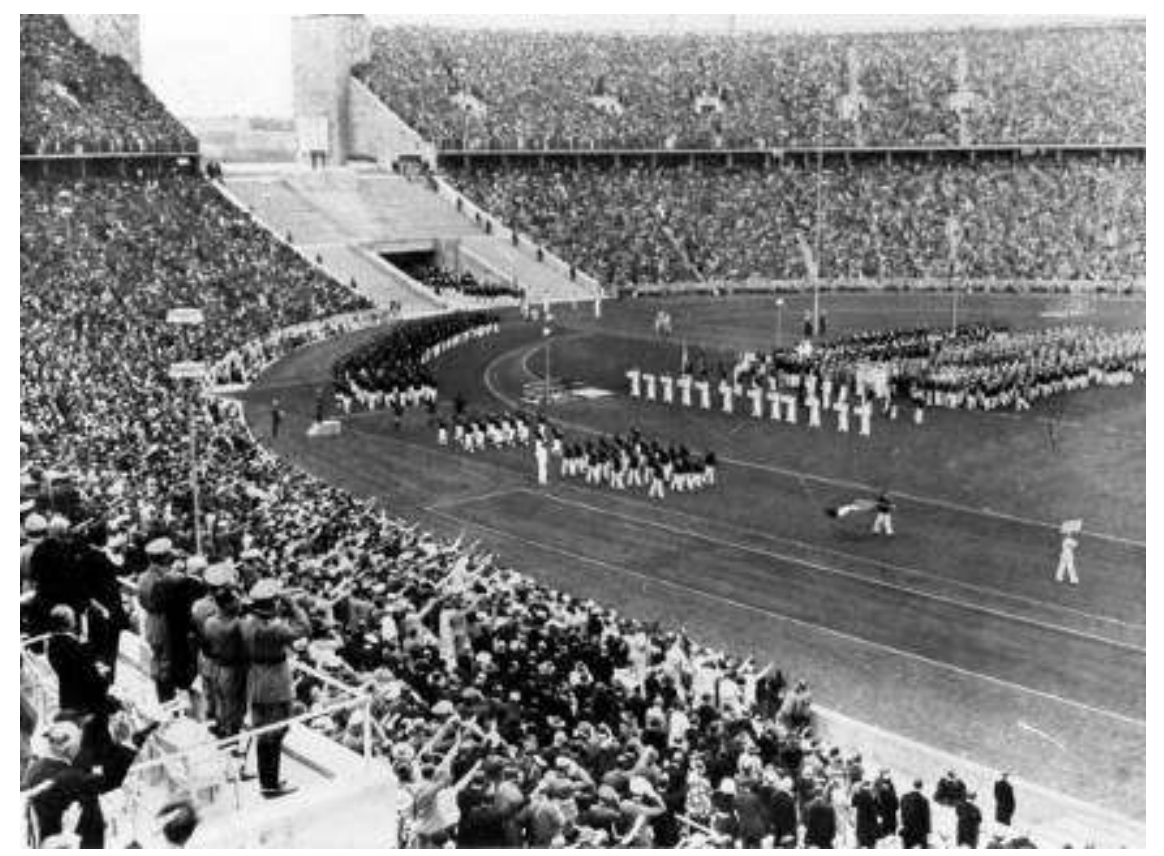

"Le défilé des délégations dans le grand stade olympique : le passage des athlètes français », dans L'Illustration, 8 août 1936.

Certes, cette mise en scène n'est pas propre aux Jeux de Berlin et caractérise plus globalement le rituel olympique, mais les nazis ont investi celui-ci de significations idéologiques nouvelles en lui conférant un écho dans la présence marquée d'uniformes militaires au cours de l'événement ${ }^{33}$. Ils ont établi de ce fait un parallélisme significatif entre les divers types de «bataillons" nationaux que forment athlètes et militaires. Les athlètes français et étrangers se trouvent ainsi assimilés malgré eux à la mise en forme idéologique des Jeux.

L'exemple précédent illustre enfin le dernier corps collectif mis en scène par la photographie de presse, celui de la foule du stade, que l'on aperçoit en train de répondre par le salut hitlérien/olympique à la délégation française - un geste qui a été abondamment commenté par la presse. On y distingue également, dans le coin inférieur gauche, la tribune officielle et les délégués nazis en uniforme. Loin de figurer l'enthousiasme désordonné, la foule des Jeux emblématise elle aussi l'ordre et la canalisation de l'énergie nationale par le sport, la symbiose collective de l'Erlebnis. 


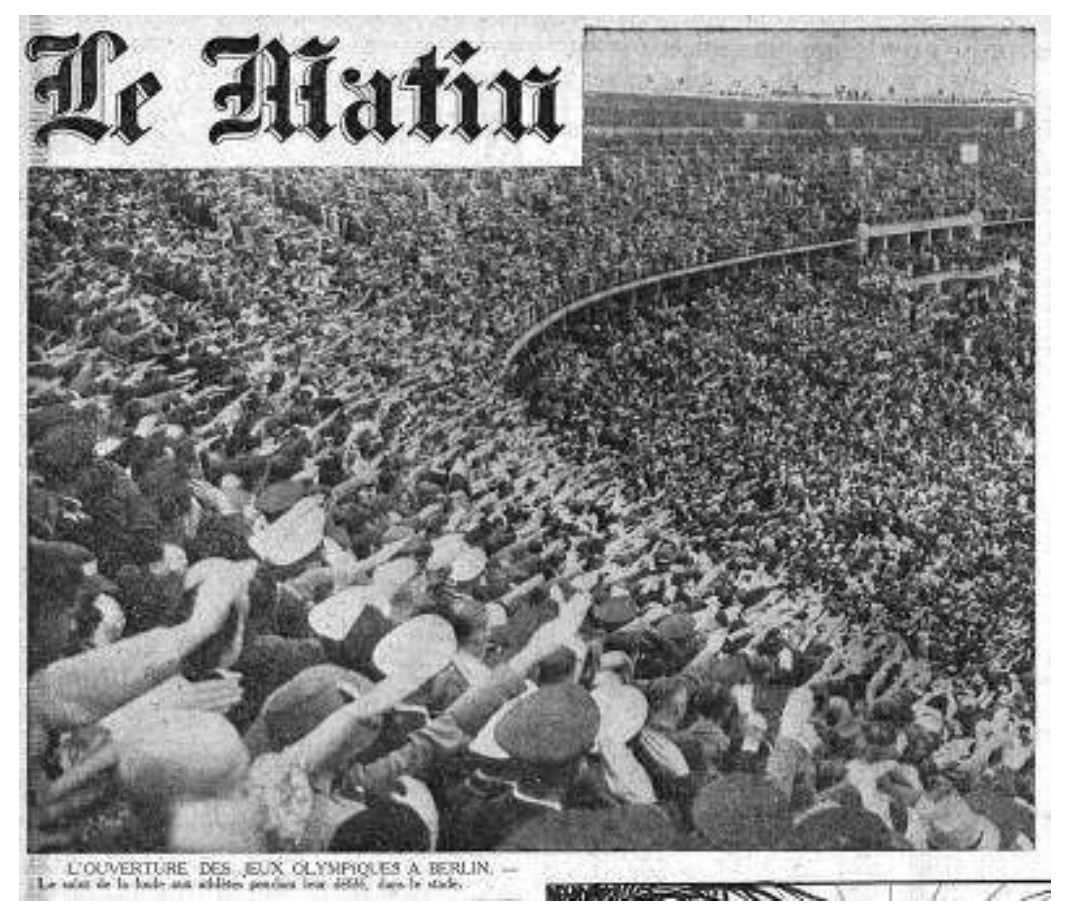

«L'ouverture des Jeux olympiques à Berlin. Le salut de la foule aux athlètes pendant leur défilé, dans le stade », dans Le Matin, 3 août 1936, p. 8.

sujet principal de la photographie, la foule, véritable marée humaine qui emplit le cadre de l'image, et dont l'immensité est accentuée par la vue en plongée, effectue presque unanimement le salut hitlérien. Corps compact et anonyme (d'autant que les individus aux premiers plans nous tournent le dos), elle est instrumentalisée à son insu en produisant une démonstration de ferveur populaire tout comme du succès que constituent les Jeux au point de vue de l'ordre et de l'organisation. Encore une fois, c'est de manière implicite que ces images de foule sont porteuses de l'idéologie nazie, dans le rapprochement avec l'iconographie national-socialiste diffusée par ailleurs. On trouve maintes représentations similaires de corps militaires et de foules ordonnées dans l'iconographie officielle nazie des années trente qui, de même, « exaltent la géométrie de l'ordre, l'uniformité des comportements, le dynamisme des gestes, la vigueur de la jeunesse et la détermination des faciès ${ }^{34}$ ". La foule olympique disposée dans le stade immense prolonge aussi le projet artistique du théâtre Thing, où l'amphithéâtre circulaire se voulait le moyen pour le "peuple d'intérioriser à travers la parabole dramatique la Communauté [...] retrouvée ${ }^{35} »$. Elle figure le peuple communiant à travers l'événement, où préside, du centre que constitue sa tribune, le Führer.

\section{Montrer l'indicible. Juxtapositions et photomontage}

Constater la force d'imprégnation de la scénographie des Jeux dans la photographie de presse ne revient pas à dénier à celle-ci toute possibilité de critique de l'idéologie nazie. Au contraire, le pouvoir évocateur du montage et de la juxtaposition d'images est tout particulièrement désigné pour véhiculer une charge critique implicite, qui mettrait plus de pudeur, peut-être, à se loger dans les mots. Il remet en cause la transparence de l'image photographique, à laquelle se superpose un sens nouveau, dans la parataxe, et permet de détourner l'image d'agence de sa vocation initiale de propagande. La pratique 
du photomontage, qui s'apparente à l'esthétique du collage surréaliste aux rapprochements évocateurs et surprenants, tout comme la mosaïque d'images constituée dans les pages illustrées des quotidiens, sont les deux principaux moyens poétiques dont dispose la presse pour faire parler les images autrement.

Parmi les quotidiens, quelques titres comportent une page ou, à tout le moins, une rubrique dédiée à l'illustration de l'actualité par la photographie. Il s'agit de L'Intransigeant (dernière page, intitulée "L'Intranvoir »), de Paris-Soir (dernière page, sans titre), du Matin (dernière page, sans titre), du Figaro (rubrique "L'actualité par l'image ») et du Progrès (rubrique « L'actualité en images »). Sous l'impulsion de Jean Prouvost, ParisSoir est le premier quotidien des années trente à avoir établi, dès le mois de mai 1931, un tel emplacement pour la photographie ${ }^{36}$; il fut bientôt imité par ses concurrents.

Dans ces pages et rubriques qui composent une mosaïque d'actualité, les photographies des Jeux de Berlin côtoient les principaux événements contemporains, dont un événement politique de premier plan, la guerre civile en Espagne. Celle-ci débute le 18 juillet 1936, soit quelque deux semaines avant les Jeux, et se trouve médiatisée par des envoyés spéciaux. Paris-Soir et L'Intransigeant, notamment, déploient des photographes en Espagne et sont en mesure de publier leurs propres clichés du conflit. Or, la juxtaposition de ces images de guerre avec celles des Jeux olympiques produit un contraste frappant, d'autant qu'elle n'est accompagnée d'aucun commentaire explicite; sur les premières figurent des civils touchés, des immeubles dévastés et des groupes désordonnés de soldats sur le terrain, sur les secondes, ces séries bien ordonnées de corps, à l'esthétique épurée, que nous avons évoquées. Dans le quotidien d'information, où la photographie a moins pour fonction d'offrir un point de vue critique sur l'événement que de le donner à voir, en vertu de son statut de document ${ }^{37}$, le sens qui émerge de la confrontation visuelle des événements s'introduit comme en fraude dans la page illustrée.

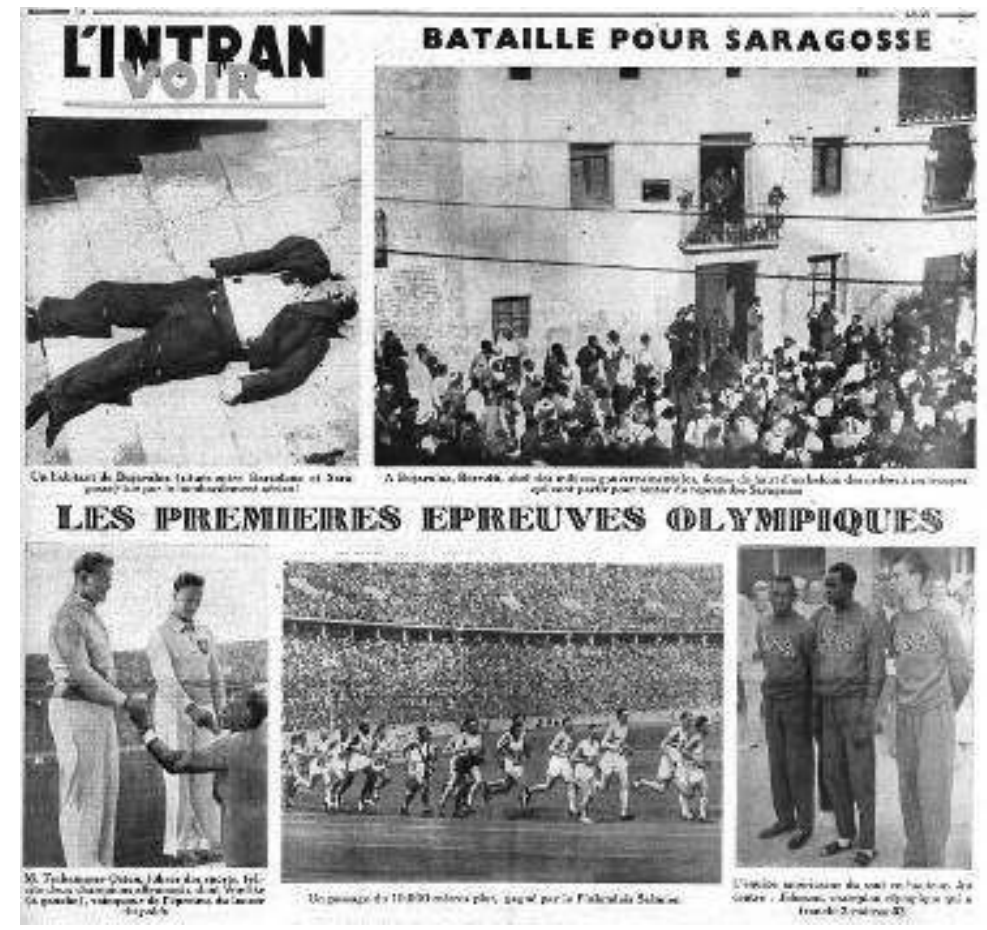

L'Intransigeant, 4 août 1936, p. 10. 
Les deux photographies du haut présentent respectivement, à gauche, le cadavre d'un « habitant de Bujaraloz [...] tué par le bombardement aérien » et, à droite, "Berrutti ${ }^{38}$ ", présenté comme le "chef des milices gouvernementales" en train de préparer ses troupes à "reprendre Saragosse ». La guerre est montrée depuis le point de vue militant du Frente Popular républicain et celui, tragique, des victimes civiles. En dessous, trois photographies illustrent les Jeux : on y voit, à gauche, deux athlètes allemands félicités par «M. Tschammer-Osten, führer des sports », au centre, un moment de la compétition du 10.000 mètres et, à droite, le champion afro-américain de saut en hauteur, Johnson, entouré de ses coéquipiers. La disposition de ce triptyque oppose symétriquement, de par la taille des photos comme l'orientation des corps des athlètes qui semblent se faire face, les Allemands aux Américains. Elle met en œuvre une syntaxe éditoriale où se lit une confrontation qui renvoie aussi bien à la compétition entre nations qu'à l'opposition des races, tout cela sous l'égide d'un important conflit opposant militants républicains et d'extrême-droite. S'il s'avère difficile de retirer une signification précise de la juxtaposition des images, celle-ci suggère à tout le moins un parallélisme troublant entre confrontations politiques et sportives. Elle renvoie en creux à l'idéologie raciste qui soustend le national-socialisme et semble la rapprocher des excès et des violences issus de la polarisation extrême du champ politique en Espagne. La critique sous-jacente impliquée par la construction paratactique est étonnante, car L'Intransigeant est un quotidien situé à droite, qui tient par ailleurs un discours assez complaisant, admiratif envers les Jeux et la remarquable réussite de l'organisation allemande ${ }^{39}$. Néanmoins, il semble difficile d'attribuer entièrement ce collage aux hasards de l'actualité, et l'on peut y voir le refuge, quoique discret, d'une critique idéologique des Jeux de Berlin. Le soin apporté à la mise en page symétrique va en ce sens. Il n'est pas rare non plus d'observer, dans les pages illustrées des quotidiens, d'autres jeux de juxtaposition, plus explicites, qui rappellent le collage surréaliste par les liens surprenants qu'ils établissent et témoignent de ce que les équipes de mise en page sont bien au fait du pouvoir de suggestion issu du rapprochement des images.

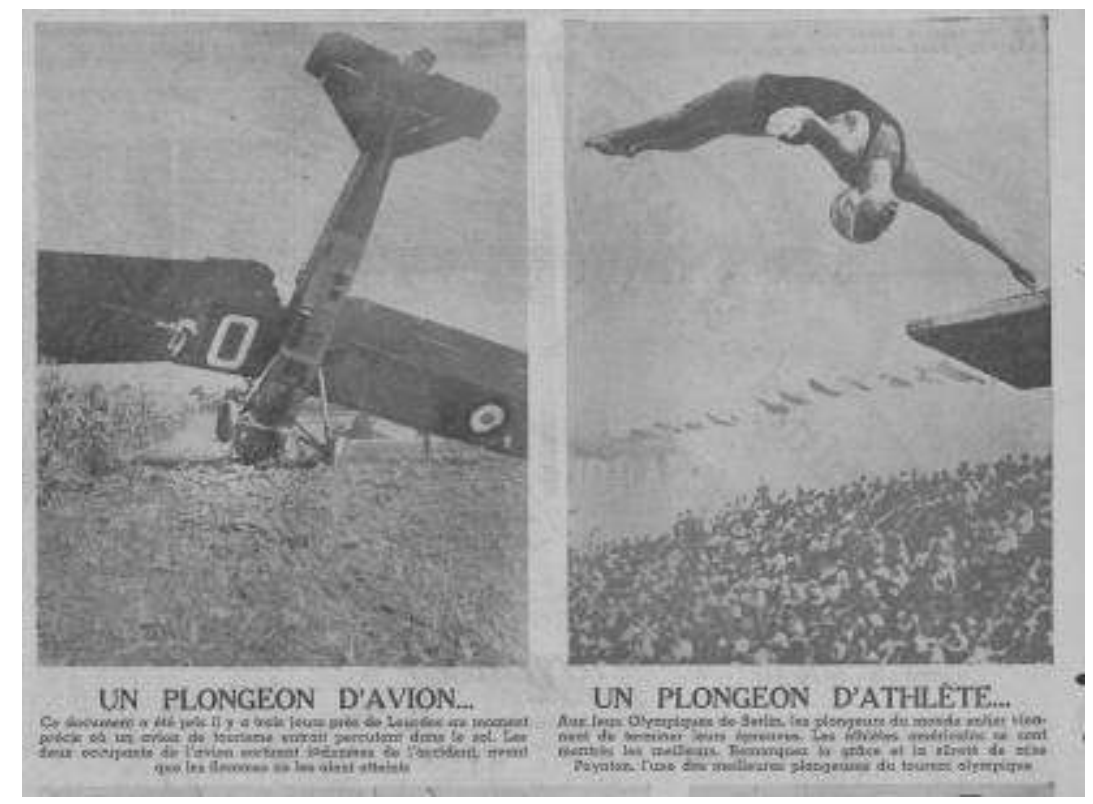

Paris-Soir, 13 août 1936, dernière page. 
Toutefois, il ne faut pas non plus surestimer la charge idéologique de la parataxe, car ce traitement n'est pas réservé aux Jeux de Berlin : au même moment, le Tour de France subit lui aussi le rapprochement incongru avec les images de la guerre d'Espagne. Sans doute l'intention de la rédaction se trouve-t-elle à mi-chemin entre la tentation de montrer l'indicible et, plus prosaïquement, la production involontaire du sens issue de l'absence de hiérarchisation des événements ou d'une forme d'éthique de l'image dans les pages illustrées. Plus explicites sont les photomontages, qui relèvent d'un geste de collage où subsiste assez peu d'équivoque.

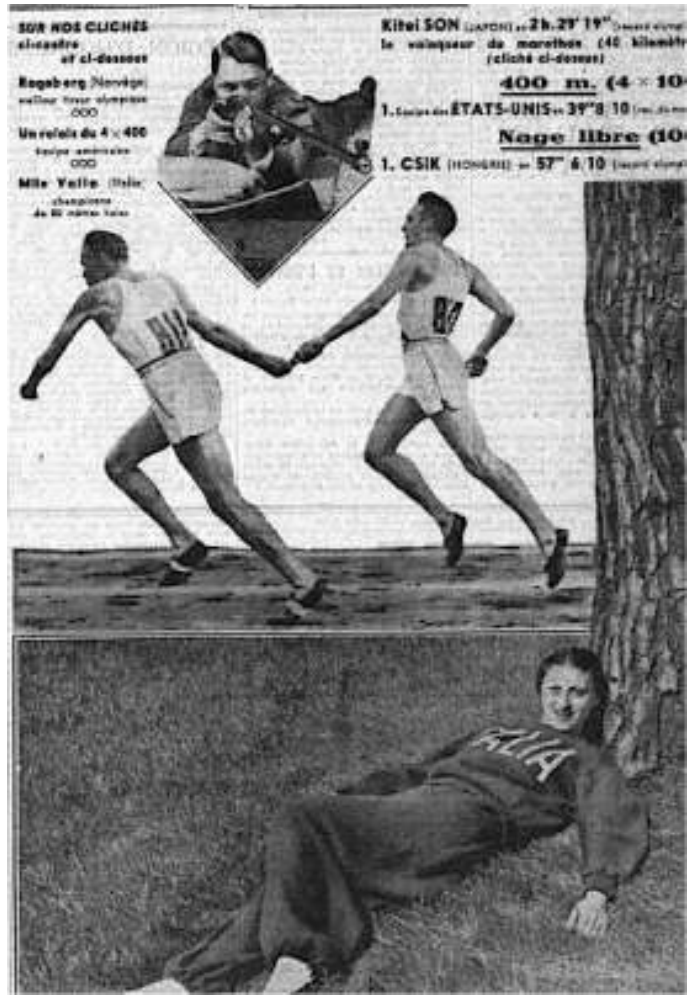

Le Petit Parisien, 10 août 1936, une. 


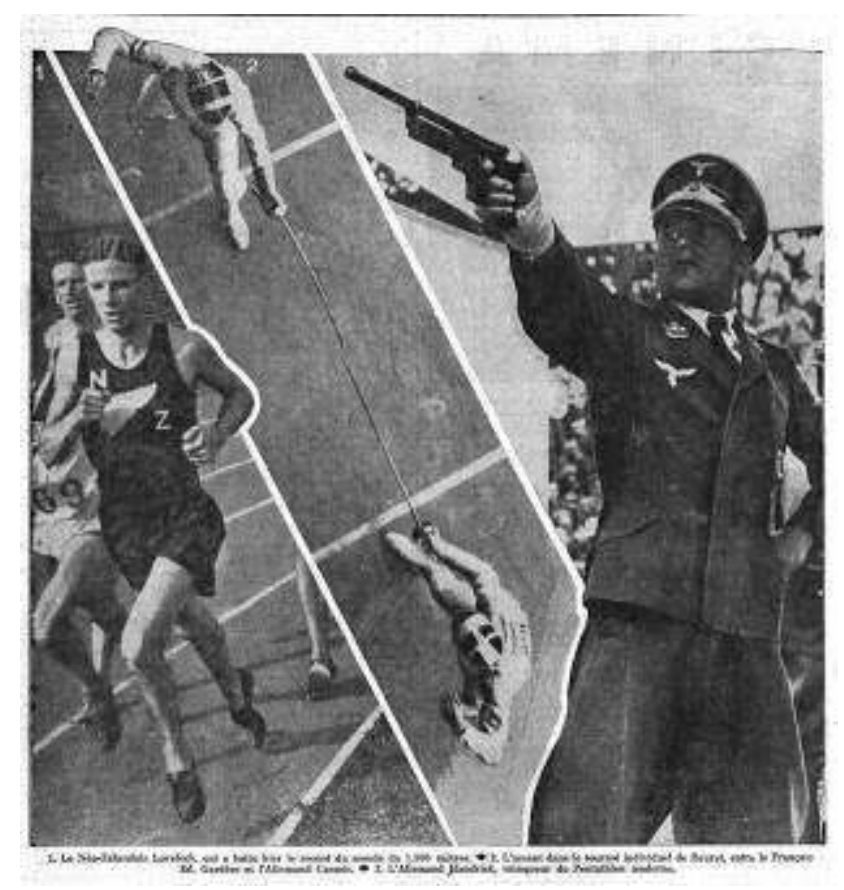

Le Figaro, 7 août 1936, p. 8.

En haut, à la une du Petit Parisien, un athlète norvégien, champion de tir, pointe son fusil directement vers la tête de l'un des coureurs américains du relais. Si elle n'a pas été recherchée, la coïncidence serait l'œuvre d'un metteur en page pour le moins maladroit, tant le geste agressif ainsi produit apparaît évident. Comme dans l'exemple de «L'Intranvoir ", le collage investit l'iconographie des Jeux d'une connotation violente qui ne s'y trouve pas a priori. Un effet semblable, plus révélateur encore, est produit par le deuxième photomontage où «l'Allemand Handrick, vainqueur du Pentathlon moderne ", revêtu d'un uniforme militaire, pointe son arme de tir vers l'un des participants d'un combat d'escrime qui oppose « le Français Ed. Gardère et l'Allemand Casmir ». Le motif de l'affrontement sportif est à nouveau déporté, par le biais de la figure d'Handrick, vers l'affrontement militaire et semble renvoyer plus précisément aux tensions entre la France et l'Allemagne. Si, comme on l'a vu, la scénographie des Jeux recherche elle-même l'association entre sport et militarisme, la récupération de celle-ci par le photomontage relaie moins le prestige et l'ordre des bataillons de corps qu'elle ne met en évidence la violence qui en découle. La création, par le collage, d'un geste agressif produit, pour le lecteur sensible à la métaphore, une mise en récit inquiétante des images : pendant que les nations « s'escriment » sur le terrain sportif, l'Allemagne se tient déjà debout, prête au vrai combat.

31 Cependant, la force d'évocation du photomontage peut aussi servir admirablement les intérêts du Reich - tout dépend de l'orientation de ceux qui le manient. Le photomontage suivant se retrouve, le 4 mars 1936, en quatrième de couverture de l'hebdomadaire Match, une publication du groupe de L'Intransigeant : 


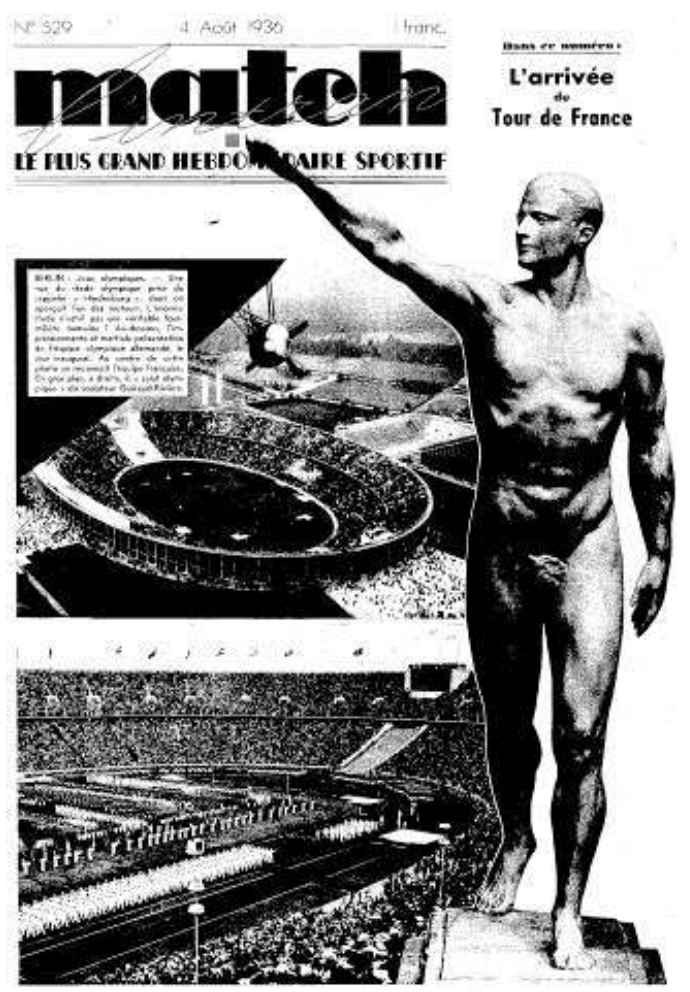

Match L'intran, 4 août 1936, couverture.

Possentiels de la scénographie des Jeux y sont colligés - le stade colossa et circulaire, en vue aérienne, la foule dense, l'ordre des délégations d'athlètes, le salut « olympique ", selon la légende, qui se confond avec le salut hitlérien, figé par l'œuvre du sculpteur français Guiraud-Rivière - dans une synthèse visuelle efficace. La légende confirme le registre laudatif de l'image, en soulignant le gigantisme du stade, «l'impressionnante et martiale présentation de l'équipe olympique allemande». L'investissement des symboles et rituels olympiques par l'idéologie nazie est ici accepté sans questionnement et relayé d'une manière qui n'aurait sans doute pas déplu à Joseph Goebbels. Dans son éditorial, le même jour, René Lehmann récuse d'ailleurs l'interprétation politique des Jeux :

Les Allemands ne se sont pas contentés de présenter avec un luxe inouï les Jeux olympiques. Ils en ont fait une nouvelle fête nationale et, sans toucher aux problèmes politiques qui nous dépassent, comme on le sait, on peut bien reconnaître qu'ils ont su persuader leur peuple de l'honneur rarissime qu'on avait fait à l'Allemagne en la chargeant d'organiser à son tour les Jeux olympiques ${ }^{40}$.

Peu importe l'orientation qui lui est conférée, le photomontage s'éloigne d'une conception documentaire de la photographie, en signalant que l'image de presse peut être instrumentalisée, détournée de sa vocation initiale, que ce soit par le geste de sélection et d'association ou par l'orientation que confère la légende choisie. Il agit un peu à la manière de la caricature, quoiqu'en mode plus équivoque. En laissant planer une part d'incertitude quant à l'intention de la rédaction, les photomontages et les constructions paratactiques des pages illustrées constituent un lieu où peut se loger une critique implicite des Jeux. Cette critique relève en partie d'un «inconscient collectif » que les surréalistes n'auraient pas récusé et qui n'ose pas se dire en toutes lettres dans la presse d'information. Elle pointe particulièrement la connotation guerrière des Jeux et, à travers celle-ci, la crainte croissante d'un conflit à venir. 
On remarquera que plusieurs des exemples observés proviennent de la presse de droite ( L'Intransigeant, Le Figaro ou, plus modéré, Le Petit Parisien); la contradiction entre l'orientation politique de ces journaux et le non-dit qui affleure dans la juxtaposition des images révèle la complexité des enjeux idéologiques entourant les Jeux de Berlin, les hésitations et les contradictions de la presse comme de l'opinion, en dehors des polarisations de l'extrême-droite et de l'extrême-gauche. Cependant, d'un point de vue global, le photomontage critique demeure assez isolé au sein de la presse française. Lors des Jeux de Berlin, la photographie aura été partiellement impuissante à tenir en échec l'entreprise efficace de propagande de l'idéologie national-socialiste qui, avant même de s'immiscer dans l'image, s'est constituée dans la mise en scène et la symbolique de l'événement.

\section{BIBLIOGRAPHY}

BROHM, Jean-Marie, 1936. Jeux olympiques à Berlin, Éditions Complexe, « La mémoire du siècle », 1983.

FRIZOT, Michel et Cédric de VEIGY, « Voir Vu de la situation allemande », dans Vu. Le magazine photographique, 1928-1940, Paris, Éditions de La Martinière, 2009, p. 162.

GEBAUER, Günter et Christoph WULF, «Les jeux de la violence », dans Actes de la recherche en sciences sociales, vol. 79, «L'espace des sports-1», 1989, p. 63-75, disponible sur Persée.

LAGRUE, Pierre, "Les Jeux nazis : propagande, complicité, naïveté », dans Le Siècle olympique. Les Jeux et l'Histoire (Athènes, 1896 - Londres, 2012), Encyclopaedia Universalis, 2013 [édition électronique].

LEENAERTS, Danielle, Petite histoire du magazine Vu (1928-1940). Entre photographie d'information et photographie d'art, Bruxelles, P.I.E. Peter Lang, 2010.

MICHAUD, Éric, Un art de l'éternité. L'image et le temps du national-socialisme, Paris, Gallimard, 1996.

POURQUERY, Didier et Philippe LABARDE, Paris-Soir. France-Soir. La photo à la une, Paris, Paris musées, 2006.

SCHMIDT, Josef, « Événement fasciste et spectacle mondial : les Jeux olympiques de Berlin en 1936 ", dans Régine ROBIN (dir.), Masses et culture de masse dans les années 30, Paris, Éditions ouvrières, « mouvement social », 1991, p. 163-179.

TARDIVON, Jean-Christophe, La photographie politique médiatisée : entre actualité et histoire. Étude de cas dans la presse française du début des années 1930, mémoire du D.E.A. en sciences du langage, EHESS, 1999. 


\section{NOTES}

1. Dans les années 1900, à la suite des agences américaines, les premières agences françaises naissent : Trempus, Meurisse, Rol. Mais c'est dans l'entre-deux-guerres qu'elles vont prendre leur essor et tisser un réseau important, avec l'ajout des agences Universal, Albapress, Interpress, Fulgur, Rapho, Alliance photo, en plus de succursales parisiennes d'agences étrangères, comme Associated Press ou Keystone. Danielle Leenaerts, Petite histoire du magazine Vu (1928-1940). Entre photographie d'information et photographie d'art, Bruxelles, P.I.E. Peter Lang, 2010, p. 52, 73-75.

2. Le quotidien dispose d'un véritable « service photographique » comprenant des photographes reporters, correspondants et pigistes, de même qu'un personnel technique (tireurs et téléphotographes). Il est le premier à se doter du dispositif de téléphotographie (bélinogramme), dès 1933. Voir Didier Pourquery, "Introduction ", dans Didier Pourquery et Philippe Labarde, Paris-Soir. France-Soir. La photo à la une, Paris musées, 2006, p. 6.; et Danielle Leenaerts, Petite histoire du magazine $\mathrm{Vu}$ (1928-1940), op. cit., p. 73.

3. Jean Prouvost, dans Paris-Soir, 2 mai 1931, une.

4. Danielle Leenaerts, Petite histoire du magazine Vu (1928-1940), op. cit., p. 18, 335-352.

5. Voir Jean-Christophe Tardivon, La Photographie politique médiatisée: entre actualité et histoire. Étude de cas dans la presse française du début des années 1930, mémoire du D.E.A. en sciences du langage, EHESS, 1999. Un numéro de $V u$, « Pas d'anarchie » (8 février 1934) sera l'objet de telles accusations.

6. Ainsi, L'Illustration mentionne les agences Associated Press, Fulgur, Keystone et Rapho, et Vu, Ullstein et Alliance-Photo ( ${ }^{\circ}$ 438, 5 août 1936, p. 928-929).

7. Ce chiffre est mentionné par Josef Schmidt, «Événement fasciste et spectacle mondial : les Jeux olympiques de Berlin en 1936 ", dans Régine Robin (dir.), Masses et culture de masse dans les années 30, Paris, Éditions ouvrières, « mouvement social », 1991, p. 173.

8. Selon Jean-Marie Brohm, dans un souci de contrôle et de propagande de l'image des Jeux de Garmisch, aucun représentant de la presse étrangère «ne fut admis à officier aux Jeux. Seuls les photographes allemands officiels furent autorisés. " Jean-Marie Brohm, 1936. Jeux olympiques à Berlin, Éditions Complexe, « La mémoire du siècle », 1983, p. 109.

9. L'Écho de Paris, 13 août 1936, p. 4.

10. Paris-Soir, 2 et 3 août 1936, une.

11. Paris-Soir, 3 août 1936, p. 8.

12. «Photographies de notre envoyé spécial Guy de Traversay », peut-on lire dans L'Intransigeant, le 8 août, en p. 10 ("L'Intranvoir »), à propos d'images illustrant « La bataille en Andalousie ».

13. Dans une certaine mesure, tous deux se confondent sans doute, au moins en partie. Selon Michel Frizot et Cédric de Veigy, l'imagerie officielle nazie est diffusée "sans retenue ni discernement [par] les agences internationales », dans les années trente. Michel Frizot et Cédric de Veigy, «Voir VU de la situation allemande», dans Vu. Le magazine photographique, 1928-1940, Paris, Éditions de La Martinière, 2009, p. 162.

14. Josef Schmidt, «Événement fasciste et spectacle mondial : les Jeux olympiques de Berlin en $1936 »$, loc. cit., p. 173.

15. L'Auto, 2 août 1936, p. 6.

16. Match, 4 août 1936, p. 4.

17. Josef Schmidt, «Événement fasciste et spectacle mondial : les Jeux olympiques de Berlin en 1936 », loc. cit., p. 165.

18. Jean-Marie Brohm, 1936. Jeux olympiques à Berlin, Éditions Complexe, « La mémoire du siècle ", 1983, p. 103. 
19. Günter Gebauer et Christoph Wulf, «Les jeux de la violence », dans Actes de la recherche en sciences sociales, vol. 79, « L'espace des sports-1», 1989, p. 63.

20. Jean-Marie Brohm, 1936. Jeux olympiques à Berlin, op. cit., p. 37-38 et 132 .

21. Sur le mythe de « l'origine solaire » du peuple aryen, l'importance du motif du flambeau et de la figure de Prométhée dans l'art national-socialiste, voir Éric Michaud, Un art de l'éternité. L'image et le temps du national-socialisme, Paris, Gallimard, 1996, p. 130.

22. Jean-Marie Brohm, 1936. Jeux olympiques à Berlin, op. cit., p. 126.

23. Nous renvoyons, de manière générale, à l'ouvrage d'Éric Michaud, Un art de l'éternité. L'image et le temps du national-socialisme, op. cit.

24. « expérience vécue (de façon affective, authentique et sincère) ». Ibid., p. 375.

25. « l'art fasciste étant en effet le Gesamtkunstwek (l'œuvre d'art totale), où l'acte politique et les effets de scène de tous les médias traditionnels et nouveaux sont fusionnés en une seule entité ». Josef Schmidt, "Événement fasciste et spectacle mondial: les jeux olympiques de Berlin en 1936 ", dans Régine Robin (dir.), Masses et culture de masse dans les années trente, op. cit., p. 164. Schmidt reprend une thèse formulée par Walter Benjamin.

26. Si l'on admet, avec Jean-Marie Brohm, qu'un aveuglement de la communauté internationale, incluant les partisans du boycott des Jeux, a prévalu quant à la convergence des valeurs de l'olympisme et du nazisme. Jean-Marie Brohm, 1936. Jeux olympiques à Berlin, op. cit., p. 169-170.

27. Éric Michaud, Un art de l'éternité. L'image et le temps du national-socialisme, op. cit., p. 235-238.

28. Jean-Marie Brohm, 1936. Jeux olympiques à Berlin, op. cit., p. 171.

29. Le générique d'ouverture de la première partie du film, «La fête des peuples ", présente en effet, dans un fondu enchaîné significatif, la pose d'un discobole sculpté prolongée par le mouvement du lancer du disque effectué par un athlète. Le même mouvement est, plus tard dans le film, décomposé avec un effet de ralenti dans la mise en scène des épreuves de lancer du disque.

30. L'esthétique photographique est alors refondée «à partir de l'exploration de ses spécificités, délestée de la référence picturale » et s'oriente vers « une photographie du monde moderne, apte à fournir de celui-ci tant une perception qu'une vision », par des photographes qui ont souvent une pratique hybride (collaborations publicitaires ou journalistiques). Danielle Leenaerts, Petite histoire du magazine $V u$ (1928-1940), op. cit., p. 76. L'exploration du mouvement et d'une esthétique de la vitesse sont l'un des thèmes que l'on retrouve dans les reportages photographiques de $V u$. Voir par exemple « Vitesse, esthétique nouvelle », dans Vu, $\mathrm{n}^{\circ} 238,5$ octobre 1932.

31. Voir Laure Demougin, Filippos Katsanos et Marie-Ève Thérenty, « Malaise à Olympie : les jeux de Berlin dans la presse française en 1936 » dans le même numéro.

32. Riefenstahl se défendra en arguant sa volonté de mettre en scène l'esthétisme du corps sportif universel, de quelque race ou nationalité qu'il soit: "J'ai tourné Olympia [Les Dieux du Stade] comme une célébration de tous les athlètes et un rejet de la théorie de la supériorité de la race aryenne." Leni Riefenstahl, Mémoires, 1987. Citée dans Pierre Lagrue, «Les Jeux nazis: propagande, complicité, naïveté ", dans Le Siècle olympique. Les Jeux et l'Histoire (Athènes, 1896 Londres, 2012), Encyclopaedia Universalis, 2013 [édition électronique].

33. Comme le précise Josef Schmidt, la corrélation entre la pratique du sport et une "armée nationale saine " se retrouve déjà dans les écrits de Pierre de Coubertin ; cependant, les Jeux de Berlin réinvestissent cette corrélation. Schmidt mentionne que les participants aux épreuves équestres portent «l'uniforme militaire de leurs pays respectif», comme en témoigne le film de Leni Riefenstahl tandis que parmi la foule, «bon nombre de spectateurs allemands portaient eux aussi l'uniforme». Joseph Schmidt, «Événement fasciste et spectacle mondial: les Jeux olympiques de Berlin en 1936 », loc. cit., p. 169-171.

34. Michel Frizot et Cédric de Veigy, "Voir VU de la situation allemande », dans Vu. Le magazine photographique, 1928-1940, op. cit., p. 162.

35. Éric Michaud, Un art de l'éternité, op. cit., p. 104. 
36. En cela, il hérite de la formule du premier quotidien illustré, Excelsior, fondé en 1910 par Pierre Lafitte, tout en la rénovant et en l'adaptant à une presse d'information populaire.

37. C'est bien le sens que connotent les titres conférés à ces pages et rubriques - «L'Intranvoir », "L'actualité en images », "L'actualité par l'image » - où le texte, placé en légende, est réduit au strict minimum nécessaire pour contextualiser la photographie.

38. Il s'agit fort probablement d'une coquille et du militant anarchiste et antifasciste Buenaventura Durruti, non «Berrutti ».

39. Ainsi s'exprime Jean de Lascoumettes, dans un article publié le jour précédent («Et maintenant, faites vos jeux", dans L'Intransigeant, 3 août 1936) : "Il faudrait évidemment employer le mot de colossal. Mais ce terme a quelque chose, dans notre langue, de péjoratif ou d'ironique. Il y a bien un synonyme! Et donc, si nous admettons que les Allemands, dans l'organisation des jeux de la Onzième Olympiade ont visé au colossal, reconnaissons qu'ils ont atteint le grandiose. / Car telle fut la cérémonie d'ouverture des Jeux. Certes, une solennité aussi religieuse ne conviendrait pas exactement au besoin de fantaisie ou à la légèreté de notre race latine. Mais, tel, il entretient et favorise une mystique olympique qui a bien besoin d'être aidée pour ne pas mourir. / [...] Et la cloche d'appel qu'on eût prise pour le tocsin, en fermant les yeux, retrouvait, quand nos regards se reposaient sur le stade, la douceur cristalline des appels. [...] Et l'on ne trouve pas si ridicule le geste du berger grec, venu avec la flamme symbolique, remettant au chancelier du Reich un rameau d'olivier symbolique lui aussi - et qu'on voudrait d'un symbolisme parfait - venu des coteaux ensoleillés de l'Hellade ».

40. René Lehmann, « Les sports. Les gens. Les faits ", dans Match, 4 août 1936, p. 2.

\section{ABSTRACTS}

Pendant les Jeux olympiques de Berlin, les photoreporters étrangers ont été encadrés par les autorités nazies et ont fourni, de ce fait, une masse d'images relativement homogène aux différents titres de la presse française. Outre le contrôle des photographes sur les lieux, la scénographie préalable des Jeux olympiques, obéissant aux principes de l'art et de l'esthétisme nazis, a elle aussi contribué à l'uniformisation des images de l'événement. Le spectacle sportif, médiatisé par la photographie, devient un spectacle des corps dans lequel se lisent des connotations idéologiques; au corps idéalisé de l'athlète, dont les pauses évoquent la sculpture antique et l'idéal aryen, répond le corps collectif des foules ordonnées et des militaires en uniforme sur fond d'étendards nazis. Cependant, la presse illustrée dispose aussi d'un langage propre pour contourner ou dévoyer la mise en forme idéologique préalable de l'événement: la retouche, le photomontage, la juxtaposition et la disposition des clichés inscrivent dans la page $\mathrm{du}$ journal des critiques latentes et parfois même violentes, quoique souvent non dites, de l'événement.

\section{INDEX}

Mots-clés: jeux olympiques, 1936, médias, presse, photoreportage, photomontage 


\section{AUTHOR}

\section{MÉLODIE SIMARD-HOUDE}

Université Paris 1 Panthéon-Sorbonne

Mélodie Simard-Houde s'intéresse aux poétiques journalistiques, aux échanges entre presse et littérature, à la culture médiatique et aux imaginaires sociaux. Elle enseigne et poursuit un postdoctorat au Centre d'histoire du XIX ${ }^{\mathrm{e}}$ siècle de l'Université Paris 1 Panthéon-Sorbonne, dans le cadre duquel elle s'intéresse à l'imaginaire aéronautique dans la presse et la littérature sérielle. En juin 2015, elle a soutenu sous les directions de Guillaume Pinson et de Marie-Ève Thérenty une thèse intitulée Le Reporter, médiateur, écrivain et héros. Un répertoire culturel (1870-1939), portant sur les représentations du reporter ainsi que sur la poétique du reportage de la III ${ }^{\mathrm{e}}$ République. On peut retrouver ses contributions notamment dans les revues Romantisme, Études françaises, Mémoires du livre, Interférences littéraires et sur la plateforme numérique Médias 19. 